\title{
Legitimidade Ativa da Defensoria Pública para a Propositura de Ação Civil Pública: interpretação a partir dos paradigmas constitucionais
}

\author{
Lucélia Sena Alves $^{1}$
}

Resumo: Este estudo tem o propósito de analisar criteriosamente a legitimidade dada à Defensoria Pública pela Lei n. 11.448/2007 para a propositura de Ação Civil Pública, contextualizando-a nos paradigmas constitucionais. A escolha do tema deu-se pela importância que a Instituição tem na efetivação do acesso à justiça e na garantia do Estado Democrático de Direito. Também foram analisados os papéis de outras instituições, como o Ministério Público, na concorrência dessa legitimação ativa e sua imprescindibilidade para a construção de uma ordem jurídica mais justa. A pesquisa valeu-se de análises pertencentes a diversos campos do saber humano, tais como Direito Constitucional, Direito Processual e Sociologia Jurídica.

Palavras-chave: Defensoria Pública. Legitimidade. Ação Civil Pública.

\begin{abstract}
The purpose of this study is to minutely analyze the legitimacy provided to the Public Defender's office by law 11.448/2007, for filing Public Civil Actions, in the light of a constitutional doctrine. The reason for choosing such topic is the importance of this institution for a greater access to justice and in the guarantee of The Democratic State of Law. The article also discusses the legal role of other institutions, such as the Public Prosecutor's office, to file civil public actions and to build a more just legal system. This article has profited from analyses from other areas of human knowledge, such as Constitutional Law, Civil and Criminal Procedure Law and Legal Sociology.
\end{abstract}

Keywords: Public Defender's office. Legitimacy. Public Civil Actions.

\section{Introdução}

O estudo do acesso à justiça, consagrado pela clássica obra de Mauro Cappelletti e Bryant Garth (1998), vem se tornando cada vez mais atual, na medida em que a nova ordem processualística transformou o enfoque de seu conceito.

1 Graduada pela Universidade de Itaúna. Foi pesquisadora do Programa Institucional de Iniciação Científica da Universidade de Itaúna. Advogada. E-mail: luceliasenalves@ gmail.com. 
Originalmente, o acesso à justiça era visto como uma garantia de se viabilizar a todos o exercício do direito de ação. Na interpretação atual, o acesso à justiça deve ser entendido como uma garantia do Estado Democrático de Direito, com a finalidade de efetivação da tutela jurisdicional.

A Lei n. 11.448/2007 dispõe sobre a legitimação da Defensoria Pública para a defesa dos direitos difusos e coletivos, o que se traduz em um avanço na efetivação da garantia constitucional de acesso à justiça. Muitas vezes, o pleito de violação desses direitos tem um trâmite burocrático e dispendioso e, se considerado individualmente, o litígio não compensaria.

Contudo, tendo em vista a contextualização constitucional de sua finalidade e os problemas estruturais das Defensorias Públicas, como a sobrecarga de serviços e reduzido quadro funcional, deve a legitimidade dessa Instituição ser interpretada em sentido estrito.

Apesar de a referida Lei não trazer quaisquer restrições, a legitimidade da Defensoria precisa ser constitucionalmente contextualizada, nos termos do artigo 134 da Constituição Federal, o que implica, consequentemente, em algumas limitações para o exercício dessa nova atribuição.

Além disso, as atuações do Estado, do Ministério Público, da OAB, bem como dos juristas de uma forma geral, demonstram-se primordiais para o alcance do acesso efetivo a uma ordem jurídica justa.

\section{Um Breve Histórico da Defensoria Pública}

Verifica-se que a primeira menção de assistência estatal aos necessitados no Brasil foi dada pelo conteúdo do artigo 10, do título LXXXIV, do Livro III, das Ordenações Filipinas, vigentes no país até 1916, quando da promulgação da primeira Constituição da República, in verbis:

Em sendo o agravante tão pobre que jure não ter bens móveis, nem de rais, nem por onde pague o aggravo, e dizendo na audiência uma vez o Pater Noster pela alma Del Rey Don Diniz, ser-lhe-á havido, como se pagasse os novecentos réis, contanto que tire de tudo certidão dentro do tempo, em que havia de pagar o aggravo. (PORTUGUAL, 2010). 
Em 1870, Nabuco de Araújo, presidente do Instituto da Ordem dos Advogados Brasileiros, impulsionou o costume de alguns membros do Instituto de dar consultas jurídicas gratuitas aos pobres, bem como defendê-los em juízo (SILVA, 2010). Até esse ponto, a ideia de assistência jurídica aos necessitados tinha uma conotação relacionada à caridade.

Somente em 1934, com a promulgação da Constituição daquele ano, surgiu a proteção constitucional do acesso dos necessitados à justiça, permanecendo desde então, expressamente, como direito fundamental do cidadão, com exceção da Carta de 1937, a qual foi silente a esse respeito. Com a evolução dos paradigmas constitucionais, surge uma nova conotação para a assistência judiciária aos hipossuficientes: a de dever jurídico.

Entretanto, a determinação para a criação de uma instituição específica, responsável pela assistência judiciária gratuita aos necessitados, deu-se somente com a Constituição Federal de 1988, a qual a denominou Defensoria Pública.

Segundo o III Diagnóstico da Defensoria Pública (BRASIL, 2009), realizado em 2009, as Defensorias Públicas Estaduais têm, em média, 16 anos. A mais antiga delas é a do estado do Rio de Janeiro, instalada em 1954, e a mais nova é a de São Paulo, instalada em 2006. É 26 o número de estados que possuem Defensoria Pública, sendo que somente o estado de Santa Catarina ainda não possui Instituição instalada.

Atualmente, o Brasil se destaca no cenário internacional pela constitucionalização da Defensoria Pública, como demonstrado em estudo realizado pelo Observatório Latino Americano de Política Criminal (OLAPOC), do Instituto Brasileiro de Ciências Criminais (IBCCRIM), por ser, dentre os 31 países estudados, um dos únicos a incluir a Instituição como órgão estatal constitucionalmente assegurado. (IBCCRIM, 2010).

A evolução e o fortalecimento da Defensoria são evidentes. A Instituição está sendo cada vez mais reconhecida pela sua imprescindibilidade, como instrumento de garantia dos direitos fundamentais. Por isso, a importância de seu estudo. 


\section{A Defensoria Pública no Estado Democrático de Direito}

A origem dos direitos humanos é incerta. Alguns apontam que as primeiras manifestações foram na Babilônia (2000 a.C.) (DIMOULIS; MARTINS, 2008), outros no Código de Hamurabi (1690 a.C.), e há também os que apontam ser na Grécia Antiga e na Roma Republicana (ALTAVILA apud MORAES; SILVA, 1984), e outros, ainda, no Jusnaturalismo Moderno, dos direitos irresistíveis, denominados inatos por Kant (ALVES; PIMENTA, 2004).

Não havendo consenso acerca de sua origem, constata-se, entretanto, que a sua evolução deu-se em razão da trajetória política da humanidade em busca de melhores condições de vida.

A clássica obra a respeito do acesso à justiça, de Mauro Cappelletti e Bryant Garth (1998), trata dessa trajetória através da narrativa da evolução do conceito de acesso à justiça.

Nos séculos XVIII e XIX, vigoravam os preceitos individualistas nos estados liberais burgueses, nos quais o acesso se limitava ao direito formal do indivíduo de propor ou contestar uma ação. O Estado de Direito caracterizava-se pela submissão ao império da lei, pela divisão de poderes, independentes e harmônicos entre si, bem como pelo enunciado e garantia dos direitos individuais (DIAZ apud ALVES; PIMENTA, 2004). Em consequência disso, aqueles que não podiam custear a proteção judicial do Estado eram deixados à própria sorte.

Mais tarde, com as conquistas oriundas de lutas da humanidade em busca da garantia aos direitos humanos fundamentais, o conceito de acesso foi substituído pelo de Estado Social de Direito, no qual a principal preocupação era assegurar o bem-estar social, com ênfase, principalmente, na saúde, na educação e na previdência social.

Depois, com os novos anseios da população em busca da efetivação desses direitos, surge o Estado Democrático de Direito, no qual o que importa não é mais a existência de um direito formal, mas, sim, a efetividade dos direitos humanos, assegurando-os constitucionalmente. 
O Brasil, acompanhando essa evolução mundial, torna-se, com a promulgação da Constituição de 1988, um Estado Democrático de Direito e, como tal, em sua maioria, os direitos e garantias fundamentais são constitucionalmente assegurados. $\mathrm{O}$ direito de acesso à justiça é um desses direitos e, nas palavras do professor Gregório Assagra de Almeida (2003, p. 68), “deve ser concebido como o mais fundamental dos direitos, como o mais básico dos princípios processuais e como uma garantia constitucional fundamental."

Podemos notar o reconhecimento de tal importância pelo poder constituinte há mais de 20 anos, pela leitura do disposto no artigo $5^{\circ}, \mathrm{LV}$, da Constituição vigente (BRASIL, 1988): “[...] aos litigantes, em processo judicial ou administrativo, e aos acusados em geral são assegurados o contraditório e a ampla defesa, com os meios e recursos a ele inerentes [...]"; e LXXIV: “[...] o Estado prestará assistência jurídica integral e gratuita aos que comprovarem insuficiência de recursos [...]" (BRASIL, 1988).

O exame do cotidiano evidencia uma longa trajetória até a plena efetivação do acesso à justiça, exigindo-se, nas palavras de Boaventura de Sousa Santos (2007), uma verdadeira "revolução democrática da justiça” (p. 46). Nessa trajetória, a Defensoria Pública, constitucionalmente incumbida da "orientação jurídica e defesa dos necessitados em todos os graus" (op cit. p. 46) é de transcendental importância. Boaventura de Sousa Santos (2007) afirma, ainda, que "a Revolução democrática da justiça exige a criação de uma outra cultura de consulta jurídica e de assistência e patrocínio judiciário, em que as defensorias públicas terão certamente um papel muito relevante" (op cit. p. 46).

A Defensoria Pública foi prometida pelo poder constituinte de 1988 como uma das vias assecuratórias do direito de acesso à justiça, constituindo uma "instituição essencial à função jurisdicional do Estado, incumbindo-lhe a orientação jurídica e a defesa, em todos os graus, dos necessitados, na forma do art. 5º LXXIV." (BRASIL, 1988, art. 134).

Determinada a sua criação em 1988, somente com a sua Lei Orgânica Nacional (LC n. 80, de 1994) é que houve a estruturação da mesma, embora já houvessem Defensorias Públicas nos estados do Rio de Janeiro (instalada em 1954) e de Minas Gerais (instituída em 1981). (BRASIL, 2006). 
Passados mais de 20 anos dessa inovação, o exame do cotidiano evidencia uma longa trajetória até a plena efetivação do acesso à justiça aos necessitados através dessa Instituição.

Um possível ponto de partida para essa revolução pode ter se dado com a Emenda Constitucional n. 45, que fortaleceu as Defensorias Públicas, concedendo-lhes autonomia funcional e administrativa, e o poder de iniciativa de sua proposta orçamentária. Além disso, por meio de diploma infraconstitucional, dotou-se a Defensoria de legitimidade para a propositura de Ação Civil Pública, o que lhe permite atuar na defesa do meio ambiente, dos direitos consumeristas, da ordem urbanística, dos bens e direitos de valor artístico, estético, histórico, turístico e paisagístico, da infração da ordem econômica, bem como de outros direitos difusos e coletivos.

A nova atribuição dada pela Lei n. 11.448/2007 dispõe sobre a legitimação da Defensoria Pública para defesa dos direitos difusos e coletivos, o que se traduz em um avanço na efetivação do acesso à justiça. Muitas vezes, o pleito de violação desses direitos tem um trâmite burocrático e dispendioso e, se considerado individualmente, o litígio não compensaria.

Observa-se, contudo, que, apesar de ser uma Instituição de suma importância para a efetivação dos direitos dos necessitados, os quais, em um país em desenvolvimento como o Brasil, são maioria, a Defensoria Pública sofre diversas limitações, dentre as quais podemos citar o seu reduzido quadro funcional e institucional.

Diante dessa realidade, a atuação da Instituição nessa nova atribuição, deve ser contextualizada constitucionalmente, de modo a atender aos anseios do seu público-alvo (necessitados), sem qualquer tipo de prejuízo.

\section{A Defesa dos Necessitados: paradigma constitucional para a atuação das Defensorias Públicas}

A Defensoria Pública, em razão do artigo 134 da Constituição Federal, deve atuar na defesa dos necessitados. 
O conceito de necessitados não deve ser entendido no sentido estrito ou pelo aspecto econômico (ausência de recursos materiais), como o artigo $4^{\circ}$ da Lei n. 1.060/1950 quis implantar (BRASIL, 1950), mas, sim, no sentido amplo ou pelo aspecto jurídico (carência jurídica), referido por Mauro Cappelletti, no sentido de vulnerabilidade das pessoas em face das relações sociojurídicas existentes na sociedade contemporânea (GRINOVER apud BRITO, 2008).

Nesse sentido:

E nessa visão parece necessário rever o antigo conceito de assistência judiciária aos necessitados, porque, de um lado, assistência judiciária não significa apenas assistência processual, e porque, de outro lado, necessitados não são apenas os economicamente pobres, mas todos aqueles que necessitam de tutela jurídica: o réu revel no processo crime, o pequeno litigante nos novos conflitos que surgem numa sociedade de massa, e outros mais que podem emergir em nossas rápidas transformações sociais. (BRITO, 2008, p. 18).

Como já exposto, o novo enfoque da assistência judiciária aos pobres não tem a conotação de caridade, mas, sim, de dever jurídico, no qual os juristas devem se atentar, no caso concreto, ao princípio da razoabilidade e da proporcionalidade, para que não obste a efetivação da assistência judiciária.

No caso das Defensorias Públicas, esse novo enfoque do conceito de hipossuficientes encontra-se respeitado, conforme se extrai do III Diagnóstico da Defensoria Pública:

Os Defensores Públicos-Gerais foram indagados sobre os critérios utilizados para que uma pessoa possa ser atendida pela Defensoria Pública. Do ponto de vista abstrato, os critérios possíveis de aplicação são: renda, patrimônio pessoal, patrimônio familiar, valor da causa, natureza da causa, valor e natureza da causa. Deve-se observar que, em determinados casos, a prestação do serviço da Defensoria Pública não depende da insuficiência econômica do assistido. Assim, por exemplo, na defesa criminal, será nomeado um Defensor Público ao acusado caso não constituir um advogado. Igual- 
mente nos casos de exercício da curadoria especial não importa a condição econômica da parte defendida, posto que lhe deve ser assegurado o direito de defesa. Nessas hipóteses, caso a parte patrocinada pela Defensoria tenha condições de pagar advogado, deverá efetuar o pagamento em favor da instituição. (BRASIL, 2009, p. 179).

Um exemplo de nova interpretação do conceito de necessitados pode ser dado através da possibilidade de deferimento do pedido de assistência judiciária às pessoas jurídicas, desde que comprovem, diferentemente do que ocorre com as pessoas físicas, a insuficiência de recursos. (STF, 2002).

Também, em relação a esse novo conceito, Ada Pellegrini Grinover aduz:

Isso porque existem os que são necessitados no plano econômico, mas também existem os necessitados do ponto de vista organizacional. Ou seja, todos aqueles que são socialmente vulneráveis: os consumidores, os usuários de serviços públicos, os usuários de planos de saúde, os que queiram implementar ou contestar políticas públicas, como as atinentes à saúde, à moradia, ao saneamento básico, ao meio ambiente etc. (GRINOVER, 2008, p. 13).

Essa nova conceituação de necessitados, bem como as novas atribuições concedidas pele Lei n. 11.448/2007, implicam num novo modo de atuação dos defensores públicos, os quais sempre o fizeram de modo individual e agora passam a atuar de modo coletivo.

A possibilidade de coletivização das demandas só traz benefícios ao público-alvo das Defensorias Públicas, no que tange à eficácia e à celeridade, conforme explicam Adriana Fagundes Burger e Christine Balbinot (2008 p.36):

$\mathrm{Na}$ realidade, a propositura das demandas coletivas otimiza a prestação jurisdicional e, dada a abrangência da eficácia subjetiva da coisa julgada formada nesse tipo de ação, assume um papel político relevante em nossa sociedade. 
O problema de acesso efetivo à justiça tem sido melhorado por intermédio dos Juizados Especiais, do Ministério Público e, principalmente, das Defensorias Públicas que, apesar de terem alguns problemas como o orçamento, a escassez de defensores públicos e a universalidade em relação ao seu público-alvo, desempenham um importante trabalho de amenização das desigualdades junto ao Poder Judiciário brasileiro.

Por essa razão, discordamos do ilustre professor Alexandre Freitas Câmara (2008, p. 49) no que diz respeito à qualidade de demandante do Ministério Público em ações cíveis na defesa de interesses individuais privados, asseverando:

[...] estou convencido (e sigo, aqui, linha de pensamento muito próxima à de um dos mais notáveis processualistas contemporâneos, o professor italiano Franco Cipriani) de que o Ministério Público deveria sair do processo civil, não mais atuando nos feitos dessa natureza. [...] Essa legitimidade extraordinária do Ministério Público se justificava em outra época, em que as pessoas não tinham qualquer consciência de seus direitos (e, por isso, não os exerciam) ou, então, não tinham condições de postular proteção para eles (o que se devia, em grande parte, à ausência da Defensoria Pública).

Plausível seria esse argumento se desconsiderássemos a realidade nacional. Segundo o II Diagnóstico da Defensoria Pública no Brasil,

O Brasil conta com 1,48 defensor público para cada 100.000 habitantes, enquanto dispõe de 7,7 juízes para cada grupo de 100.000 habitantes, e 4,22 membros do Ministério Público para o mesmo grupo de habitantes. (BRASIL, 2006, p. 106).

Também, segundo o Instituto Brasileiro de Geografia e Estatística (IBGE), o índice de analfabetismo no Brasil de pessoas com mais de 15 anos foi de 10\% da população, em 2007 (BRASIL, 2008), sem contar o índice de analfabetos funcionais. Na Itália, por outro lado, o índice de alfabetização foi de 99.1\% em 2006 (UNESCO, 2009). Impossível é, pois, a comparação entre capacidade de entendimento dos direitos entre as po- 
pulações desses dois países, o que inviabiliza a comunhão de pensamentos doutrinários acerca do assunto.

Pretendemos dizer que, embora o Ministério Público tenha atribuições que não a defesa dos necessitados, para a qual a Constituição legitima a Defensoria Pública, o mesmo tem papel fundamental na efetivação do acesso à justiça, em consideração à realidade do país.

O Ministério Público não tem que priorizar as causas cíveis ou deixar de priorizar as de outra natureza, porém não deve deixar de ter essa atribuição, sob pena de contribuição no aumento do desequilíbrio social existente, já que, diminuindo o número de legitimados, consequentemente restringe-se a acessibilidade. Também, por força do artigo 127 da Constituição da República (1988, p. 89), essa legitimidade deve ser entendida no sentido amplo, como defesa da ordem jurídica, do regime democrático e dos interesses sociais (ALMEIDA, 2003).

A Constituição impõe ao Estado o dever de proporcionar aos desprivilegiados a condição essencial de titulares do direito e, como tais, possuidores de dignidade e respeito social.

Com efeito, a Defensoria Pública enquanto Instituição essencial à função jurisdicional do Estado,

[...] não pode (e não deve) ser tratada de maneira inconsequente, porque, de sua adequada organização e efetiva institucionalização, depende a proteção jurisdicional de milhões de pessoas - carentes e desassistidas -, que sofrem inaceitável processo de exclusão que as coloca, injustamente, à margem das grandes conquistas jurídicas e sociais (STF, 2009, p. 2-3).

Adriana Fagundes Burger e Christine Balbinot (2008, p. 33) concluem:

[...] o Estado passa a ter o dever de criar e manter as Defensorias Públicas como forma de instrumentalizar a população carente de meios para exercer o direito fundamental do controle jurisdicional, buscando, por meio da propositura de ações, a efetividade das promessas constitucionais [...]. 
Destarte, o Poder Público tem papel fundamental, principalmente, no que tange à sua institucionalização. $\mathrm{O}$ número de Defensorias Públicas existentes no país é insuficiente. A cobertura total do serviço no país abrange 39,7\% das comarcas e sessões judiciárias existentes, ou seja, mais da metade não dispõe dos serviços da Defensoria Pública. O nordeste, região com o menor número de desenvolvimento humano no Brasil, é a região com a menor porcentagem de comarcas atendidas pelas mesmas. O estado de Santa Catarina não possui Defensoria Pública Estadual. Apesar da necessidade de mais defensores públicos estaduais no país, a média de concursos públicos no período de 1998 a 2004 era de somente 3,9 por ano. (BRASIL, 2006).

Nesse sentido, constata-se que, de nada valerão os direitos e as liberdades, se os fundamentos sob os quais são baseados acabam sempre sendo violados por aquele detentor do poder de efetivá-los.

\section{Conflito de Atribuições entre Defensoria Pública e Ministério Público}

A nova redação do artigo $5^{\circ}$, da Lei n. $7.347 / 1985$, dada pela Lei n. 11.448/2007, legitimou a Defensoria Pública para a propositura de Ação Civil Pública. Em decorrência disso, parte do Ministério Público vem se opondo a essa legitimação.

A discussão iniciou-se quando a Associação Nacional dos Membros do Ministério Público (Conamp) ajuizou uma Ação Direta de Inconstitucionalidade (ADI 3943, relatoria da Ministra Carmen Lúcia), no Supremo Tribunal Federal, em oposição à legitimidade da Defensoria Pública para a propositura de Ação Civil Pública, sob o argumento de usurpação de atribuições próprias dessa Instituição, calcado no artigo 129 da Constituição Federal. Entende, também, que a legitimação da Defensoria deve ser excluída para a tutela dos direitos difusos, já que a seleção de beneficiados em ações coletivas torna-se inviável, podendo, assim, extrapolar a tutela, além do seu público-alvo (os hipossuficientes).

José dos Santos Carvalho Filho (2007, p. 127), porém, assevera acerca dessa legitimidade do Ministério Público: 
Entretanto, somente se pode admitir tal legitimidade se os interesses individuais homogêneos se qualificarem como indisponíveis, porque, como já visto, a constituição deixou claro que a tutela do MP deve ser dirigida a interesses sociais e individuais indisponíveis (art. 127).

Outrossim, foi a manifestação do STJ (2006) a respeito da legitimidade da Defensoria Pública para a propositura de Ação Civil Pública:

CONSTITUCIONAL E PROCESSUAL CIVIL. AÇÃO CIVIL PÚBLICA. DEFESA DOS INTERESSES DOS CONSUMIDORES DE ENERGIA ELÉTRICA. ILEGITIMIDADE ATIVA DA DEFENSORIA PÚBLICA. CÓDIGO DE DEFESA DO CONSUMIDOR. INAPLICABILIDADE. NULIDADE DO ACÓRDÃO RECORRIDO. INOCORRÊNCIA.

I - O Tribunal a quo julgou satisfatoriamente a lide, pronunciando-se sobre o tema proposto, tecendo considerações a cerca da demanda, tendo apreciado a questão afeita à tempestividade da apelação interposta pelo ora recorrido, entendendo que lhe é assegurado o prazo em dobro para recorrer, não havendo, portanto, que se falar em nulidade do acórdão hostilizado.

II - A hipótese em tela diz respeito a ação civil coletiva, ajuizada pelo Núcleo de Defesa do Consumidor da Defensoria Pública do Estado do Rio de Janeiro - NUDECON, em defesa dos consumidores de energia elétrica daquele Estado, contra Light Serviços de Eletricidade S/A e CERJ - Companhia de Eletricidade do Rio de Janeiro, em que postula a ilegalidade de artigos da Portaria $\mathrm{n}^{\circ}$ 466/97 do DNAEE, com a abstenção das rés em suspender o fornecimento de energia elétrica, bem como em calcular a dívida dos consumidores com base em tal regramento legal, condenando aquelas na repetição de valores pagos indevidamente.

III - A Defensoria Pública não possui legitimidade para propor ação coletiva, em nome próprio, na defesa do direito de consumidores, porquanto, nos moldes do art. 82, inciso III, do Código de Defesa do Consumidor, não foi especificamente destinada para tanto, sendo que sua finalidade institucional é a tutela dos necessitados.

IV - O Supremo Tribunal Federal, reforçando o entendimento sufragado, por meio da ADIN no 558-8/MC, exarou entendimento no sentido da legitimidade da Defensoria Pública para intentar ação 
coletiva tão-somente para representar judicialmente associação desprovida dos meios necessários para tanto, não possibilitando a atuação do referido órgão como substituto processual, mesmo porque desprovido de autorização legal, a teor do art. $6^{\circ}$ do CPC.

$\mathrm{V}$ - Recursos especiais providos, para determinar a ilegitimidade ativa ad causam do NUDECON, com a consequente extinção do processo sem julgamento de mérito, restando prejudicada a apreciação acerca do prazo em dobro para o recorrido apelar.

O principal argumento favoravelmente à legitimação ativa da Defensoria Pública é baseado na redação do artigo 129, da Constituição Federal, o qual trata das atribuições do Ministério Público e, em seu inciso III, dispõe da legitimidade para promover o inquérito e a Ação Civil Pública, para a proteção do patrimônio público e social, do meio ambiente e de outros interesses difusos e coletivos. Porém, em seu parágrafo $1^{\circ}$, o mesmo artigo dispõe: “A legitimação do Ministério Público para as ações civis previstas neste artigo não impede a de terceiros, nas mesmas hipóteses, segundo o disposto nesta Constituição e na lei." (BRASIL, 1988).

Com a leitura do referido artigo, nota-se que o próprio legislador constituinte, em sua preocupação em assegurar o acesso à justiça, não restringiu a atribuição para promover a Ação Civil Pública ao Ministério Público, com o intuito de garantir o maior número possível de legitimados, visando à garantia da efetivação dos direitos fundamentais.

Nesse sentido, Cristina Gonçalves (2007, p. 20) leciona:

A democratização dos instrumentos de acesso à Justiça, antes de dividir, deve ser vista como um fator de soma na busca de uma sociedade mais livre, justa e solidária, efetivando dessa forma um dos mais importantes objetivos fundamentais da República Federativa do Brasil previsto na Constituição Federal.

A Defensoria Pública não busca a exclusividade na propositura da Ação Civil Pública, mas que, isto sim, essa ação seja um meio para atacar e corrigir as violações de direitos, em especial de direitos sociais, sofridas pela população carente.

$[\ldots]$

A Defensoria Pública pretende desempenhar suas atribuições com responsabilidade, imbuída do senso de que seus membros são ser- 
vidores públicos que devem salvaguardar os direitos da população pobre brasileira, que representa significativa parcela da população nacional. E, por isso, temos certeza da constitucionalidade da legitimidade conferida à Defensoria para propor Ação Civil Pública.

Além disso, a legitimidade da Defensoria para a propositura de Ação Civil Pública foi concedida anteriormente à Lei n. 11.448/2007, já que a Lei n. 8.078/1990, o Código de Defesa do Consumidor, já previu, em seu artigo 82, tal legitimação, in verbis: "III - as entidades e órgãos da Administração Pública, direta ou indireta, ainda que sem personalidade jurídica, especificamente destinados à defesa dos interesses e direitos protegidos por este código.” (BRASIL, 1990).

Em seu parecer, a pedido da Associação Nacional dos Defensores Públicos (ANADEP), Ada Pellegrini Grinover (2008, p. 10-11) asseverou:

Por outro lado, não se percebe como essa legitimação, concorrente e autônoma, poderia afetar aquela do MP, impedindo ao parquet exercer plenamente suas atividades, conforme alega a requerente em relação à Defensoria Pública. A inclusão desta no rol dos diversos legitimados em nada interfere com o pleno exercício das atribuições do MP, que continua a detê-las.

$[\ldots]$

A nova norma legal permite, simplesmente, que a Defensoria Pública venha somar esforços na conquista dos interesses ou direitos difusos, coletivos e individuais homogêneos da sociedade, podendo inclusive agir em litisconsórcio com o Ministério Público. Por outro lado, a ampliação da legitimação à ação civil pública representa poderoso instrumento de acesso à justiça, sendo louvável que a iniciativa das demandas que objetivam tutelar interesses ou direitos difusos, coletivos e individuais homogêneos seja ampliada ao maior número possível de legitimados, a fim de que os chamados direitos fundamentais de terceira geração - os direitos de solidariedade - recebam efetiva e adequada tutela.

Em nome do acesso efetivo a uma ordem jurídica justa, o objetivo dessa discussão não deve ser a exclusividade dos legitimados para a propositura de Ação Civil Pública, o que acarretaria um retrocesso do exer- 
cício da democracia, mas justamente o contrário. O fundamento para a efetivação do acesso à justiça deve ser a ampliação do rol de legitimados para a propositura desse tipo de ações, como acreditamos ter sido a intenção do legislador constituinte, concretizando, assim, o exercício da tutela coletiva, e o Estado Democrático de Direito.

\section{Legitimidade Ativa da Defensoria Pública na Ação Civil Pú- blica: interpretação conforme a Constituição Federal}

Segundo Mauro Cappelletti e Bryant Garth (1998), há três posições básicas acerca do acesso à justiça. A primeira é conhecida como "primeira onda renovatória", referente à assistência judiciária para os pobres. A segunda, é conhecida como "segunda onda renovatória", refere-se à representação dos interesses difusos, a qual visa à proteção dos chamados interesses coletivos. E a última e "terceira onda renovatória" relaciona-se à reforma do sistema processual na busca da efetivação dos direitos, o que, segundo os autores, não é alcançada no sistema processual civil atual.

O processo coletivo apresenta-se como uma expressão da segunda onda renovatória. Nas palavras do Professor Gregório Assagra de Almeida (2003, p. 22), pode ser o mesmo conceituado como:

[...] o ramo do direito processual que possui natureza de direito processual-constitucional-social, cujo conjunto de normas e princípios a ele pertinente visa disciplinar a ação coletiva, o processo coletivo, a jurisdição coletiva, a defesa no processo coletivo e a coisa julgada coletiva, de forma a tutelar, no plano abstrato, a congruência do ordenamento jurídico em relação à Constituição e, no plano concreto, pretensões coletivas em sentido lato, decorrentes dos conflitos coletivos ocorridos no dia-a-dia da conflituosidade social.

Em uma interpretação constitucional, a ampliação do rol de legitimados para a propositura de Ações Civis Públicas dada pela Lei n. 11.448/2007 proporcionou a junção das três ondas renovatórias supracitadas, já que a Defensoria Pública é constitucionalmente incumbida da defesa dos interesses dos necessitados (pobres em sentido amplo), podendo, 
desde 2007, propor ações coletivas (segunda onda), bem como viabilizar a transformação do sistema tradicional, no sentido de possibilitar a otimização das demandas e do trâmite processual, em busca do efetivo acesso à justiça.

Os benefícios da propositura das ações coletivas são incalculáveis, já que nos deparamos a todo momento com a ineficácia do sistema tradicional individualista, atribuída, na maior parte das vezes, à morosidade do sistema. E um fator que contribui para essa morosidade é o grande número de ações individuais, as quais, muitas vezes, poderiam ser concentradas em ações coletivas.

A partir da interpretação constitucional, deve-se concluir, então, que os limites da atuação da Defensoria Pública nas demandas coletivas devem ser interpretados a partir do texto da Constituição Federal, no sentido de tutelar, precipuamente, os necessitados, nos termos do seu artigo 134.

O teor do artigo 20, IV, do anteprojeto de Código Brasileiro de Processo Coletivo parece ser a solução para a limitação da Defensoria Pública na atuação como legitimada para propor Ações Civis Públicas, in verbis:

[...] A Defensoria Pública, para a defesa dos interesses ou direitos difusos e coletivos, quando a coletividade ou os membros do grupo, categoria ou classe forem necessitados do ponto de vista organizacional, e dos individuais homogêneos, quando os membros do grupo, categoria ou classe forem, ao menos em parte, hipossuficientes. (BRASIL, 2007, p. 14)

Salienta-se que o novo conceito de necessitados abrange, também, aqueles chamados socialmente vulneráveis, conceito que nos ensina Ada Pellegrini Grinover (2008, p. 13):

Não cabe ao Estado indagar se há ricos ou pobres, porque o que existe são acusados que, não dispondo de advogados, ainda que ricos sejam, não poderão ser condenados sem uma defesa efetiva. Surge, assim, mais uma faceta da assistência judiciária, assistência aos necessitados, não no sentido econômico, mas no sentido de 
que o Estado lhes deve assegurar as garantias do contraditório e da ampla defesa.

Além disso, não pode prevalecer o argumento de que a Defensoria não seria legitimada para a propositura de Ação Civil Pública, em razão de não ser possível garantir a presença exclusiva das pessoas pobres, já que, inclusive, o direito a ser tutelado pode ser de interesse tanto de necessitados, quanto dos não necessitados.

Nesse contexto, a defensora pública da União, Vânia Márcia Damasceno Nogueira (2008, p. 459), aduziu:

Desta forma, observa-se que não é necessário que toda a coletividade, grupo ou interessados assistidos pela Defensoria Pública na tutela dos direitos transindividuais sejam compostos exclusivamente por pessoas necessitadas, visto que a parcela da sociedade beneficiada pela ação proposta pode não ser hipossuficiente. Ademais, o direito a ser tutelado pode ser comum a ambas as pessoas pobres e ricas. A Defensoria não poderia eximir-se do dever de possibilitar o acesso à justiça ao carente porque o não carente seria também beneficiado, haja vista que o corolário da dignidade humana e acesso à justiça são também impositivos para o Estado Democrático de Direito.

Assim, devem os defensores públicos, então, sempre que se depararem com demandas em defesa dos direitos coletivos e difusos, se esquivarem, o quanto possível, de atuações individualistas, sem abandoná-las, e aproveitar a nova prerrogativa dada pela Lei n. 11.448/2007, observando, sempre, o seu público-alvo: os hipossuficientes em sentido amplo.

\section{Proposta Interpretativa a partir do artigo $5^{\circ}$, LXXIV, da Cons- tituição Federal}

A Defensoria, como já analisado, não consegue atender ao enorme número de necessitados existente. É necessário, pois, a união de todos os juristas para que reconheçam a sua função social e entendam "que qualquer regulamentação processual, inclusive a criação ou o encorajamento 
de alternativas ao sistema judiciário formal tem um efeito importante sobre a forma como opera a lei substantiva." (CAPPELLETTI, 2008, p.12)

Algumas alternativas já estão sendo encorajadas e criadas, como por exemplo, a Resolução n. 62, de 10 de fevereiro de 2009, do Conselho Nacional de Justiça, que regulamenta o cadastro de advogados voluntários que poderão se agregar à Defensoria Pública mediante convênio na tentativa de diminuição dos gargalos do Judiciário. Também disciplina a realização de convênios ou termos de cooperação com instituições de ensino para a prestação de assistência voluntária, que nesses casos poderá ser prestada por estagiários, orientados pelos advogados das Instituições. (CONSELHO NACIONAL DE JUSTIÇA, 2009).

Bastante pertinente mostra-se, também, a aplicação, através da codificação, do direito processual coletivo no ordenamento jurídico, o qual é explicado pelo Professor Gregório Assagra de Almeida:

[...] já que o direito processual coletivo visa tutelar sempre um direito ou interesse social, tanto que o megaescopo da jurisdição é a pacificação social com justiça, ao mesmo tempo em que é fundamental a tutela jurisdicional coletiva com canal de educação do povo; e ainda, o Estado quando torna efetivos direitos ou interesses massificados, mesmo que pela via jurisdicional, está atuando de forma a transformar positivamente a realidade social, com a diminuição das diferenças socais. (ALMEIDA, 2003, p. 24).

Muitas alternativas também devem ser encorajadas, como, por exemplo, a conciliação, a mediação e a arbitragem. Inclusive, a nova redação do artigo $4^{\circ}$ da Lei Complementar n. 80 de 1994, proposta pelo Projeto de Lei Complementar n. 28, de 2007, incentiva a utilização desses institutos pela Defensoria Pública, in verbis:

II - promover, prioritariamente, a solução extrajudicial dos litígios, visando a composição entre as pessoas em conflito de interesses, por meio de mediação, conciliação, arbitragem e demais técnicas de composição e administração de conflitos. (BRASIL, 1994). 
Além disso, hodiernamente, a melhor doutrina encoraja a legitimação do próprio indivíduo para a propositura de ações coletivas. Nesse sentido, o professor Gregório Assagra de Almeida (2003, p. 541) nos ensina:

[...] tem-se que ação coletiva é o instrumento processual colocado à disposição de determinados entes públicos ou sociais, arrolados na Constituição ou na legislação infraconstitucional - na norma mais restrita, o cidadão -, para a defesa via jurisdicional dos direitos coletivos em sentido amplo.

O fortalecimento e a ampliação das ações coletivas podem ser um efetivo instrumento para o aperfeiçoamento do acesso à justiça, na medida em que amenizam os entraves relacionados aos custos processuais e o desequilíbrio das partes. (AISENBERG, 2007).

Em suma, todos os meios de otimização e celeridade processuais, que garantam o efetivo acesso à justiça, se tornam bem vindos, de modo a somar, e não restringir as garantias do Estado Democrático de Direito.

\section{Conclusões}

Os anseios atuais da população em relação ao Poder Judiciário exigem cada vez mais a criação de mecanismos inovadores e céleres para uma prestação jurisdicional efetiva e justa. O sistema processual civil da atualidade ainda é deficitário em relação a esses novos anseios.

A legitimação da Defensoria Pública para a propositura de Ação Civil Pública, dada pela Lei 11.448/07, representa um avanço na luta contra o desequilíbrio social brasileiro e a efetivação dos direitos e garantias fundamentais dos hipossuficientes, garantindo a eles meios de otimização de suas demandas.

Apesar de a referida lei não trazer qualquer restrição à atuação da Defensoria nessa nova atribuição, a mesma deve ser contextualizada a partir dos paradigmas constitucionais, a fim de tutelar os direitos dos socialmente vulneráveis. 
A Defensoria Pública vem tendo o reconhecimento da importância de seu trabalho cada vez mais, como pela Lei 11.448/07, bem como pela recém-promulgada Lei Complementar 132/09, tonando-se a cada dia uma instituição mais sólida e imprescindível.

No entanto, muito mais há de ser feito em busca de uma ordem jurídica justa e efetiva, sobretudo por parte do Estado, que, por força constitucional, deve assegurar a efetivação dos direitos e garantias fundamentais, através do fortalecimento estrutural e funcional de suas instituições, as quais são garantidoras das promessas constitucionais, e, consequentemente, do Estado Democrático de Direito.

\section{Referências}

AISENBERG, Victor. As ações coletivas à luz do acesso à justiça e da legitimidade. Revista Jurídica do Ministério Público do Estado de Minas Gerais, Belo Horizonte: De Jure, n. 8, p. 471-486, jan./jun. 2007.

ALMEIDA, Gregório Assagra de. Direito Processual Coletivo Brasileiro: Um novo ramo do direito processual. São Paulo: Saraiva, 2003.

ALVES, Cleber Francisco; PIMENTA, Marilia Gonçalves. Acesso à Justiça em preto e branco: Retratos Institucionais da Defensoria Pública. Rio de Janeiro: Lúmen Júris, 2004.

BRASIL. Lei $n$. 1.060, de 5 de fevereiro 1950. Estabelece normas para a concessão de assistência judiciária aos necessitados. Disponível em: $<$ http://planalto.gov.br/ccivil_03/Leis/L1060.htm>. Acesso em: 11 jan. 2011.

BRASIL. Senado. Constituição da República Federativa do Brasil de 1988. Brasília, DF: Congresso Nacional, 1988.

BRASIL. Lei n. 8.078, de 11 setembro de 1990. Dispõe sobre a proteção do consumidor e dá outras providências. Disponível em: $<$ http://www. planalto.gov.br/ccivel_03/Leis/L8078.htm>. Acesso em: 11 jan. 2011. 
BRASIL. Lei Complementar n. 80, de 12 de janeiro de 1994. Organiza a Defensoria Pública da União, do Distrito Federal e dos Territórios e prescreve normas gerais para sua organização nos Estados, e dá outras providências. Disponível em: < http://www.planalto.gov.br/ccivil_03/ Leis/LCP/Lcp80.htm>. Acesso em: 11 jan. 2011.

BRASIL. Ministério da Justiça. Instituto Brasileiro de Direito Processual. Anteprojeto de Código Brasileiro de Processos Coletivos. Última Versão. Disponível em: <http://www.mpcon.org.br/site/portal/jurisprudencias_ detalhe.asp?campo=2897>. Acesso em: 27 maio 2010 .

BRASIL. Ministério da Justiça. II Diagnóstico da Defensoria Pública de 2006. Disponível em: <http://www.anadep.org.br/wtksite/downloads/ Diag_defensoria_II.pdf $>$. Acesso em: 27 maio 2010.

BRASIL. Ministério do Planejamento, Orçamento e Gestão. IBGE Instituto Brasileiro de Geografia e Estatística. Comunicação social de 24 de setembro de 2008. Disponível em: <http://www.ibge.gov.br/home/ presidencia/noticias/noticia_impressao.php?id_noticia $=1233>$. Acesso em: 27 maio 2010.

BRASIL. Ministério da Justiça. III Diagnóstico da Defensoria Pública de 2009. Disponível em: <http://www.anadep.org.br/wtksite/IIIdiag DefensoriaP.pdf $>$. Acesso em: 27 maio 2010.

BRITTO, Adriana. A Evolução da Defensoria Pública em Direção à Tutela Coletiva In: SOUSA, José Augusto Garcia de (Coord.). A Defensoria Pública e os Processos Coletivos: comemorando a Lei Federal n. 11.448, de 15 de janeiro de 2007. Rio de Janeiro: Lumen Juris, 2008 .

BURGER, Adriana Fagundes; BALBINOT, Christine. A Dimensão Coletiva da Atuação da Defensoria Pública a Partir do Reconhecimento de sua Legitimidade Ativa para a Propositura das Ações Civis Públicas. In: SOUSA, José Augusto Garcia de (Coord.). A Defensoria Pública e os Processos Coletivos: comemorando a Lei Federal n. 11.448, de 15 de janeiro de 2007. Rio de Janeiro: Lumen Juris, 2008. 
CÂMARA, Alexandre Freitas. Legitimidade da Defensoria Pública para Ajuizar Ação Civil Pública: um Possível Primeiro Pequeno Passo em Direção a uma Grande Reforma. In: SOUSA, José Augusto Garcia de (coord.). A Defensoria Pública e os Processos Coletivos: comemorando a Lei Federal 11.448, de 15 de janeiro de 2007. Rio de Janeiro: Lumen Juris, 2008.

CAPPELLETTI, Mauro; GARTH, Bryant. Acesso à Justiça. Tradução de Ellen Gracie Northfleet. Fabris, Porto Alegre: 1988.

CARVAlHO FILHO, José dos Santos. Ação Civil Pública: comentários por artigo. Rio de Janeiro: Lumen Juris, 2007.

CONSELHO NACIONAL DE JUSTIÇA. Resolução n. 62, de 10 de fevereiro de 2009. Disponível em: <http://www.cnj.jus.br/index. php?option=com_content\&view=article\&id=6577:resolucao-no-62-de10-de-fevereiro-de-009\&catid=57:resolucoes \&Itemid=512>. Acesso em: 28 jul. 2009.

DIMOULIS, Dimitri; MARTINS, Leonardo. Teoria Geral dos Direitos Fundamentais. São Paulo: Revista dos Tribunais, 2008.

GONÇALVES, Cristina Guelfi. A democratização do acesso à justiça. ADPERJ. 3 set. 2007. Disponível em: <http://www.adperj.com.br>. Acesso em: 27 maio 2010.

GRINOVER, Ada Pellegrini. Parecer a pedido a ANADEP - Associação Nacional de Defensores Públicos - de 16 de setembro de 2008. Disponível em: $<$ http://www.sbdp.org.br/arquivos/material/542 ADI3943_pareceradapellegrini.pdf>. Acesso em: 27 maio 2010.

IBCCRIM. Instituto Brasileiro de Ciências Criminais - OLAPOC. A Defensoria Pública na América Latina e sua constitucionalização. Disponível em: <http://www.ibccrim.org.br/site/olapoc/centroDados. php?acao $=$ selCentros\&id=28>. Acesso em: 14 jun. 2010.

MORAES, Humberto Peña de; SILVA, José Fontenelle T. da. Assistência Judiciária: sua gênese, sua história e a função protetiva do Estado. 2. ed. Rio de Janeiro: Liber Juris, 1984. 
NOGUEIRA, Vânia Márcia Damasceno. Legitimidade da Defensoria Pública para propositura da Ação Civil Pública em comentário de acórdão do Superior Tribunal de Justiça. Revista Jurídica do Ministério Público do Estado de Minas Gerais, Belo Horizonte: De Jure, n. 11, p. 447-464, jul./dez. 2008.

PORTUGAL. Ordenações Filipinas. Disponível em: <http://www1.ci.uc. pt/ihti/proj/filipinas/13p695.htm>. Acesso em: 20 jan. 2010.

SADEK, Maria Tereza. Acesso à Justiça. São Paulo: Konrad Adenauer Stiftung, 2001.

SANTOS, Boaventura de Sousa. Para uma Revolução Democrática da Justiça. São Paulo: Cortez, 2007.

SILVA, João Fernando Vireira da. Estudo comparativo entre a Assistência Judiciária Gratuita no Brasil e o Apoio Judiciário em Portugal, p. 58. Disponível em: <http://publique.rdc.puc-rio.br/direito/ media/Silva_n30.pdf $>$. Acesso em: 28 jul. 2009.

SILVA, José Fontenelle Teixeira da. Defensoria Pública no Brasil - minuta histórica. Página pessoal. Disponível em: $<\mathrm{http}: / / \mathrm{www}$. jfontenelle.net/>. Acesso em: 20 jan. 2010.

SOUSA, José Augusto Garcia de (Coord.). A Defensoria Pública e os Processos Coletivos: comemorando a Lei Federal n. 11.448, de 15 de janeiro de 2007. Rio de Janeiro: Lumen Juris, 2008.

STJ. Superior Tribunal de Justiça. REsp 734176/RJ, Ministro FRANCISCO FALCÃO, PRIMEIRA TURMA, DJ 27 de março de 2006, p. $196, \mathrm{RB}$, v. 511 , p. 25.

UNESCO. Instituto para estatísticas. Educação na Itália. Disponível em: $<$ http://stats.uis.unesco.org/unesco/TableViewer/document. aspx ?ReportId $=121 \& I F \_L a n g u a g e=e n g \& B R \_C o u n t r y=3800>$. Acesso em: 28 jul. 2009.

Recebido em: 27/09/2010

Revisado em: 12/11/2010 Aprovado em: 02/12/2010 